\title{
Assessing Intercultural Communicative Competence in College English Teaching
}

\author{
Jing Zheng ${ }^{1}$ \\ ${ }^{1}$ English Department, North China Electric Power University, Beijing, China \\ Correspondence: Jing Zheng, 3-202, Building 104, North Fourth Ring East Road, Chaoyang District, Beijing, China \\ 102206. Tel: 86-010-13141337911. E-mail: zhengjing79@126.com
}

Received: June 18, 2014 Accepted: June 27, $2014 \quad$ Online Published: June 28, 2014

doi:10.5430/ijelt.v1n2p73 URL: http://dx.doi.org/10.5430/ijelt.v1n2p73

This research is funded by the Fundamental Research Funds for the Central Universities, No. 13MS54.

\begin{abstract}
Intercultural competence is a concept that seems to be transparent, universally accepted, understood and used, but which has received many differing definitions and never been assessed comprehensively inside and outside academia. In the setting of intercultural competence acquisition in college English teaching, this paper identifies cultural knowledge, attitudes toward other cultures and culture behavior as the three components of intercultural competence and discusses the methods of assessing them respectively. College students' competence in intercultural communication should be evaluated in both a summative and a formative way with the combined use of written test and formative assessment methods like performance evaluation and portfolio assessment.
\end{abstract}

Keywords: intercultural competence, assessment, college English teaching

\section{Introduction}

Globalization and regional integration have brought about frequent contacts between people of different cultural backgrounds. Effective communication across cultures requires communicators to have excellent intercultural communicative competence (ICC). Teaching a foreign or second language is not simply teaching an object of academic study, but more appropriately teaching a means of communication. Communication is never out of context and because culture is a part of context, communication is seldom culture-free. It is today increasingly recognized that language teaching should stress on the cultivation of learners' ICC to endow them a competitive advantage in the ever demanding world market. Standards for Foreign Language Learning in the 21st Century published by the American Council on the Teaching of Foreign Languages proposed the five Cs standards - communication, cultures, connections, comparisons and communities - to highlight the importance of communicative competence and comprehensive use of language. A Common European Framework of Reference for Languages: Learning, Teaching, Assessment published by the European Union classifies language learners' communicative competence into six categories, each of which reflects the importance of communicative competence cultivation in foreign language learning. The 2000 edition of Teaching Syllabus for English Majors in China clearly claims the necessity of cultivating students' ICC, requiring English teaching to focus on the cultivation of students' cultural awareness, tolerance and flexibility in dealing with cultural differences.

The task of foreign language teaching to develop students' ICC determines the importance of test and assessment of ICC. Test examines learners' knowledge and competence by test tools such as test papers and shows learners' performance by scores. Assessment evaluates learners' learning process and progress achieved in a certain period of study in variable means and highlights learners' efforts and progresses in the process of learning. Test and assessment of ICC can not only measure results of ICC cultivation, but also provide feedbacks to teaching activities aiming at elevating students' ICC.

\section{Components of Intercultural Communicative Competence}

There are hundreds of definitions of ICC that have been given by researchers worldwide to serve their research 
interests. In the fields of psychology and communication, it is seen as social effectiveness (the ability to achieve instrumental as well as social goals) and appropriateness (accepted communication in a given cultural milieu). In the field of foreign language learning, it has been defined as the ability of a person to behave adequately in a flexible manner when confronted with actions, attitudes and expectations of representatives of foreign culture (Mayer, 1991). The most exhaustive and influential definition of ICC is that of Michael Byram (1997). Byram has defined five savoirs, or components of ICC--knowledge, attitudes, skills of interpreting and relating, skills of discovery and interaction and critical cultural awareness--which are complementary to a language learner's ICC. His model has a significant advantage compared to others: it sets clear objectives. Young Yun Kim (2001) breaks ICC down into three components, namely, cognitive component, affective component and operational component. In Kim's opinion, to have adequate ICC, one is required to have good knowledge of the language, as well as the good command of the pragmatic use of the language. Brian Spitsberg (2003) defines ICC as "the interaction that is perceived as effective in fulfilling certain rewarding objectives in a way that is also appropriate to the context in which the interaction occurs" and proposes that knowledge, motivation and skills are indispensable components of intercultural competence.

In China, Zhao Aiguo \& Jiang Yaming(2003) advocate that ICC should consist of language competence, pragmatic competence and operational competence. Jia Yuxin holds that ICC should consist of the system of basic communication, the affective and relational competence system, the episodic competence system and strategic competence system and discusses in detail subdivisions of each system.

With reference to the definitions mentioned above and taking the study objective of this paper into consideration, ICC is defined here as "a series of abilities needed to perform effectively and appropriately when interacting with people who speak different languages and have different cultural backgrounds".

\section{Contents of Intercultural Competence Assessment}

The assessment of ICC is a field that is rife with controversy. Part of the reason lies in the validity of the test. The validity of a test must be referenced against the skill, performance, ability, or whatever the instructional program purports to instill. In other words, unless what is being tested or assessed is clarified, adequately appropriate measurement tools cannot be developed. Therefore, before developing the method of ICC assessment, the content of assessment must be clarified.

Different from business people or other professionals in the workplace, college students acquire ICC mainly on campus. Culture has been taught as bits and pieces of information included in foreign language studies. Culture testing has traditionally measured the scattered factual knowledge of culture, rather than insights or awareness of the essence of a culture. Despite of many efforts over the last three decades, the language teaching profession has not succeeded in developing a valid standardized measuring process for culture learning. However, difficulty doesn't mean impossibility in assessing ICC. As long as reasonable goals for intercultural communication are set up for college students, it is feasible to assess their competence in intercultural contacts.

College students will later enter the real business world where they would get some personal experience of intercultural communication to improve their ICC. Before that, college English teaching should, first of all, grant them the most fundamental abilities of communicating with people across cultures. Seelye (1993) put forward the following 7 objectives of culture testing, a) the sense, or functionality, of culturally conditioned behavior; b) the interaction of language and social variables; c) conventional behavior in common situations; d) cultural connotations of words and phrases; e) evaluating statements about a society; f) researching another culture; g) attitudes toward other cultures. These objectives, to a great extent, reflect the objectives of culture teaching and could provide useful guidance for culture testing and assessment. However, these objectives are too abstract to be implemented in ICC assessment. Lafayette \& Schulz (1997) believed that culture can be learned as active cultural knowledge or passive cultural knowledge, and that there are only three culturally oriented goals that can be tested in schools in reality: knowledge, understanding, and behavior. Lafayette \& Schulz's model of culture assessment is practical and feasible, but it ignores some important contents of culture teaching such as intercultural awareness, intercultural communicative competence and culture learning abilities.

With reference with some experts' research on ICC, this paper argues that three components-- knowledge, attitude and skills - of ICC should be assessed. When cultural knowledge in language testing is mentioned, it generally refers to the following abilities: the ability to recognize cultural information or patterns, the ability to describe, or to ascribe to, the proper part of the population a pattern in the culture or social behavior, the ability to recognize a pattern when it is illustrated. This goal focuses on factual information about selected patterns of the target culture, the student's 
ability to recall, recognize, and describe cultural information. Attitude toward culture involves the student's attitude to other cultures, awareness and sensitivity of cultural differences and flexibility in dealing with culturally different ideas. The testing of cultural behavior includes the following abilities: the ability to use cultural information or patterns, the ability to react appropriately in a social situation, the ability to predict how a pattern is likely to apply in a given situation, the ability to describe or manifest an attitude important for making one acceptable in the foreign society, the ability to evaluate the form of a statement concerning a culture pattern, the ability to describe or demonstrate defensible methods of analyzing a socio-cultural whole, the ability to identify basic human purposes that make significant the understanding which is being taught. This objective refers to behavioral skills, such as the ability to act meaningfully, unobtrusively, and inoffensively in real or simulated cultural situations.

\section{Methods of Intercultural Communicative Competence Assessment}

The three components of ICC, knowledge, attitude and skills, involve cognitive science, affection and behavioral science, therefore, the ways of assessing each of them varies.

\subsection{Assessment of Cultural knowledge}

Lafayette \& Renate point out that there are three basic methods for acquiring cultural knowledge and skills: a. total uncritical immersion into a culture, defined as cultural conditioning. The student learns by imitation and stimulus-response techniques, such as a child becomes acculturated into his own society; b. critical and analytical observation of recurring incidents that demonstrate a similar pattern of cultural behavior. This method is used by anthropologists and social scientists, and should ideally be applied while totally immersed in the culture; c. guided observation of selected patterns in isolation followed by explanation and interpretation of the pattern with the help of a knowledgeable resource person (Lafayette \& Renate, 1975, pp. 104-18).

It is obvious that college English learners must depend on the third method described above. Since the students are usually exposed only to "sample" cultural incidents, the observations must, therefore, be followed by teacher-guided explanations. Factual knowledge on the history, geography, religion, art and so on of the target culture has long been included in English teaching and traditional written examination with blank filling, multiple choices, true or false questions can effectively assess students' mastery of these knowledge. Cultural knowledge on the micro level such as life style and cultural values can directly influence people's verbal and non-verbal communication and should be the key objective of culture teaching in college English education. However, this type of cultural knowledge is hard to assess because of its vast content and subtleness of perception. For the assessment of cultural knowledge on the micro level, this paper gives the following suggestions.

First, assessment of cultural knowledge on the micro level should be placed in specific situations. Cultural knowledge and the situation in which an intercultural encounter happens are inseparable. The explanation of a communicative behavior varies with situations. The situation decides whether a communicative behavior is appropriate and consistent with cultural norms.

Second, the content of cultural knowledge should be clearly defined. What have been taught should be assessed. The content of assessment limits the tasks that the students are realistically asked to perform on a test. Cultural knowledge assessed should focus on the knowledge which can influence intercultural communicative behaviors.

Third, knowledge on host culture should be included in the assessment. For a long period of time, host culture is ignored in culture teaching. However, without a deep understanding of one's own culture, a person's knowledge on intercultural communication is incomplete and unsystematic, which will in turn affect the efficiency of his intercultural communication.

\subsection{Assessment of Culture Attitude}

Attitude toward other cultures is an important component of ICC. If a student doesn't have the motivation to communicate inter-culturally or has a hostile attitude to something culturally different from his own, he will never succeed in an intercultural communicative event. Since attitude toward other cultures is related with a student's psychology and cognitive ability, it is of great difficulty to assess it. To have a general idea of a student's attitude toward culture, assessors can make use of some well-developed tools for attitude assessment such as the social distance scale (Bogardus, 1925), the semantic differential approach (Osgood, et al. 1957) and statement judgment method (Grice, 1934) according to their specific purpose of attitude assessment. What should be noted is that students' attitude toward other cultures may change with the progress of their culture studies, therefore, attitude assessment had better be carried out both at the beginning and the end of a teaching program to monitor the changes 
in attitude.

\subsection{Assessment of Cultural Behavior}

With adequate cultural knowledge and appropriate attitudes toward other cultures, how a student will behave in an intercultural communicative situation is the biggest concern of ICC teaching in language education. Culture behavior can be indirectly assessed by written test with multiple-choices, true or false questions and short answer questions to provide objective revelation of a student's competence in intercultural communication. However, written test is only an indirect way of cultural behavior assessment because what a student really does in real communicative situations and what he expects he could do is sometimes different. Written test always involves the factor of luck. Therefore, it is necessary to evaluate a student's real competence in handling intercultural encounters in a more scientific way. Performance evaluation is a supplement to written test of cultural behavior. In performance evaluation, students are assigned a specific task of intercultural communication and teachers observe their format of response to evaluate their behavior with reference to a prescribed scoring system. Since the method is task-based, the task must be carefully designed to cover the content of assessment. The scoring system should be clearly explained to the students so that they can understand the feedback the teacher gives to their performance.

Another method that could be adopted for evaluating students' cultural behavior is portfolio assessment. "A portfolio is a purposeful collection of student work that exhibits the student's efforts, progress and achievements in one or more areas. The collection must include student participation in selecting contents, the criteria for selection, the criteria for judging merit and evidence of student self-reflection" (Paulson, Paulson, and Meyer, 1991:60). A portfolio shows the students' progress at each stage whether in their learning or in their thinking, so it can record the students' growth. When used in classrooms for learning purposes, portfolios can provide an organizing structure for teacher-student feedbacks and student self-reflections. It is through self-reflection that students analyze their learning patterns and growth in order to view more clearly their progress. Portfolios encourage students to reflect on their work, to analyze their progress, and to set goals. Portfolios can be used not only to individual classes but also to individual students. And portfolio results can be used to plan instruction. A portfolio provides samples of a student over a period time, and the student can help himself/ herself determine his/her own patterns of achievements and errors. To employ portfolio assessment in cultural behavior assessment, teachers and students can follow the following procedures.

First, at the very beginning of a teaching program, the teacher and students negotiate the content of the portfolio which should reflect the teaching objectives, teaching contents and expectations of both the teacher and the students. Meanwhile, the form of assignment should be clarified. Assignments should take varied forms such as survey report, teamwork research project, oral presentation and so on. As in performance evaluation, scoring standards are important for smoothly carrying out the assessment. These standards should be comprehensive and in detail. Students should be told the schedule for completing different assignments.

Second, in the process of task completion, the teacher should provide necessary guidance and instruction to the students and master the progress of students' project.

At last, at the end of a teaching program, the teacher should organize students' self-assessment, peer-assessment and on these basis offer his/her own assessment of each student's portfolio.

Portfolio assessment is a typical formative assessment method and consistent with student-centered teaching principle. If scientifically designed and carried out in the assessment of ICC, it can constructively serve teaching of ICC on college campus.

\section{Conclusion}

Intercultural communicative competence is a concept that seems to be transparent, universally accepted, understood and used, but which has received many differing definitions and never been assessed comprehensively inside and outside academia. In the setting of intercultural competence acquisition in college English teaching, this paper identifies cultural knowledge, attitudes toward other cultures and cultural behavior as the three components of ICC and discusses the methods of assessing them respectively. College students' competence in intercultural communication should be assessed in both a summative and a formative way with the combined use of written test and formative assessment methods like performance evaluation and portfolio assessment.

Intercultural communicative competence is not permanent, and its practice and learning never end. Students should bear in their mind that ICC acquisition is a lifelong learning. 


\section{References}

Bogardus, E. S. (1925). Measuring Social Distance. Journal of Applied Sociology, 9, 299-308.

Byram, M. (1997). Teaching and Assessing Intercultural Communicative Competence. Clevedon: Multilingual Matters Ltd.

Deardorff, D. (2009) (ed.). The Sage Handbook of Intercultural Competence. London: Sage.

Grice, H. H. (1934). The Construction and Validation of a Generalized Scale to Measure Attitudes toward Defined Groups. Purdue University Bulletion, 25, 37-46.

Jia Yuxin. (2004). Intercultural Communication (in Chinese). Shanghai: Shanghai Foreign Language Education Press, 480.

Lafayette, R. C., \& Schulz, R. A. (1997). Evaluating cultural learning. In Heusinkeld (ed.).

Osgood, C. E., Tannenbaum, P. H., \& Suci, G. J. (1957). The Measurement of Meaning. Urbana: University of Illinois Press.

Paulson F. L., Paulson, P. R., \& Meyer, C. A. (1991).What Makes a Portfolio a Portfolio? Educational Leadership, February, 48(5), 60-63.

Seelye, H. N. (1993). Teaching Culture: Strategies for Intercultural Communication. Lincolnwood, Illinois: National Textbook Company.

Sercu, L. (2004). Assessing Intercultural Competence: a Framework for Systematic Test Development in Foreign Language Education and Beyond. Intercultural Education, 15(1), 7389.

Spitsberg, B., \& Cupach, W. R. (2003). Competence in Interpersonal Conflicts. New York: MacGraw Hill.

Young Yun Kim. (2001). Becoming Intercultural: An Integrative Theory of Communication and Cross-cultural Adaptation. Thousand Oaks, California: Sage Publications, Inc..

Zhao, Aiguo, \& Jiang, Yaming. (2003). Applied Cultural Linguistics (in Chinese). Shanghai: Shanghai Foreign Language Education Press. 